\title{
Narrow Framing and Long-Term Care Insurance
}

\author{
Daniel Gottlieb and Olivia S. Mitchell
}




\title{
Narrow Framing and Long-Term Care Insurance
}

\author{
Daniel Gottlieb \\ The Wharton School, University of Pennsylvania \\ Olivia S. Mitchell \\ The Wharton School, University of Pennsylvania
}

June 2015

\author{
Michigan Retirement Research Center \\ University of Michigan \\ P.O. Box 1248 \\ Ann Arbor, MI 48104 \\ www.mrrc.isr.umich.edu \\ (734) 615-0422
}

\section{Acknowledgements}

The research reported herein was performed pursuant to a grant from the U.S. Social Security Administration (SSA) funded as part of the Retirement Research Consortium through the University of Michigan Retirement Research Center (5 RRC08098401-07). The opinions and conclusions expressed are solely those of the author(s) and do not represent the opinions or policy of SSA or any agency of the Federal Government. Neither the United States Government or any agency thereof, or any of their employees, makes any warranty, express or implied, or assumes any legal liability or responsibility for the accuracy, completeness, or usefulness of the contents of this report. Reference herein to any specific commercial product, process or service by trade name, trademark, manufacturer, or otherwise does not necessarily constitute or imply endorsement, recommendation, or favoring by the United States Government or any agency thereof.

\section{Regents of the University of Michigan}

Michael J. Behm, Grand Blanc; Mark J. Bernstein, Ann Arbor; Laurence B. Deitch, Bloomfield Hills; Shauna Ryder Diggs, Grosse Pointe; Denise Ilitch, Bingham Farms; Andrea Fischer Newman, Ann Arbor; Andrew C. Richner, Grosse Pointe Park; Katherine E. White, Ann Arbor; Mark S. Schlissel, ex officio 


\title{
Narrow Framing and Long-Term Care Insurance
}

\begin{abstract}
We propose a model of narrow framing in insurance and test it using data from a new module we designed and fielded in the Health and Retirement Study. We show that respondents subject to narrow framing are substantially less likely to buy long-term care insurance than average. This effect is distinct from, and much larger than, the effects of cautiousness, risk aversion, or adverse selection, and it offers a new explanation for why people underinsure their later-life care needs.
\end{abstract}

\section{Citation}

Gottlieb, Daniel, and Olivia S. Mitchell. 2015. "Narrow Framing and Long-Term Care Insurance." Ann Arbor, MI. University of Michigan Retirement Research Center (MRRC) Working Paper, WP 2015-321.

http://www.mrrc.isr.umich.edu/publications/papers/pdf/wp321.pdf

\section{Authors' Acknowledgements}

The research reported herein was performed pursuant to a grant from the U.S. Social Security Administration (SSA) funded as part of the Michigan Retirement Research Center. Additional support was provided by the University of Michigan's Health and Retirement Study, the Pension Research Council/Boettner Center of the Wharton School, and the Department of Business Economics and Policy at the Wharton School of the University of Pennsylvania. This research is part of the NBER programs on Aging and Public Economics, and the Insurance Working Group. Programming assistance was ably provided by Yong Yu. Opinions and errors are solely those of the authors and not of the institutions with whom the authors are affiliated. 


\section{Narrow Framing and Long-Term Care Insurance*}

\section{Introduction}

Long-term care (LTC) expense is one of the largest financial r isks c onfronting the nation's growing elderly population. Long-term care includes a wide range of health and personal care services including provision of medication, as well as dressing, showering, eating, and toileting. Such services may be delivered either at home, or in a nursing home or assisted living facility. ${ }^{1}$ Though people's duration and intensity of LTC needs will vary, it is anticipated that between 50-70 percent of Americans will require long-term care at some point (Hurd et al., 2014; Brown and Finkelstein, 2008): An average 65-year old can anticipate requiring long-term care for about three years, with women needing it longer than men. Long-term care is also very

\footnotetext{
*dgott@wharton.upenn.edu (Gottlieb) and mitchelo@wharton.upenn.edu (Mitchell), The Wharton School, University of Pennsylvania. The research reported herein was performed pursuant to a grant from the U.S. Social Security Administration (SSA) funded as part of the Michigan Retirement Research Center. Additional support was provided by the University of Michigan's Health and Retirement Study, the Pension Research Council/Boettner Center of the Wharton School, and the Department of Business Economics and Policy at the Wharton School of the University of Pennsylvania. This research is part of the NBER programs on Aging and Public Economics, and the Insurance Working Group. Programming assistance was ably provided by Yong Yu. Comments and suggestions from Sarah Auster, Paul Heidhues, Nathaniel Hendren, Botond Koszegi, and Matthew Rabin are gratefully acknowledged. Opinions and errors are solely those of the authors and not of the institutions with whom the authors are affiliated. (C) 2015 Gottlieb and Mitchell. All rights reserved.
}

${ }^{1}$ See Brown and Finkelstein (2011) or Fang (2014) for recent surveys. 
costly in the United States: The median outlay for a private room in a nursing home was $\$ 240 /$ day $(\$ 87,600 /$ year) in 2014 (Genworth, 2014), or more than twice the household income of seniors on average (RWJ, 2014). Moreover, the costs of long-term care can be prohibitive, with 10-20 percent of people requiring nursing home care for longer than five years (Brown and Finkelstein, 2009).

Given the inherent riskiness of LTC costs and the important potential benefits of having long-term care insurance, it may be surprising that few Americans actually purchase such coverage. Currently only eight percent of the American population has LTC insurance, and such private insurance pays for less than 12 percent of long-term care expenditures (RWJ 2014). Public spending, mostly via the means-tested Medicaid program, covers over 60 percent of long-term care expenditures. ${ }^{2}$ In this light, economists have proposed two main reasons why Americans do not buy long-term care insurance, namely crowding-out by Medicaid (Pauly, 1990; Brown and Finkelstein, 2008; Brown, Coe, and Finkelstein, 2007), and insurers working to weed out those mostly likely to need the care via strict underwriting (Hendren, 2013). ${ }^{3}$

The present paper proposes an additional reason for why people may not buy long-term care insurance: 'narrow framing' or people's tendency to make decisions in isolation. Psychologists have noted that many people fail to account for other risks they also face, particularly when making complex decisions (c.f., Tversky and Kahneman, 1981; Kahneman and Lovallo, 1993; and Read, Loewenstein, and Rabin, 1999). Such an approach often simplifies decision-making under uncertainty, but it can also be quite costly. For instance, individuals who frame their decisions narrowly may choose first-order stochastically-dominated options (Tversky and Kahneman, 1981; Rabin and Weizsacker, 2009) and fail to diversify (Eyster and Weizsacker, 2011).

A large literature from psychology and behavioral economics documents the pervasiveness of narrow framing in the financial realm. For instance, this phenomenon implies that people

\footnotetext{
${ }^{2}$ Private LTC insurance is also uncommon outside of the United States. Among the OECD countries, for example, private insurance covers around two percent of total LTC spending. The source of expenditure varies substantially, with more than 60 percent out of pocket in Switzerland to 100 percent public expenditure in France (OECD Health System Accounts, 2010). See Colombo et al. (2011) for a discussion of the longterm care market in other countries.

${ }^{3}$ Many other factors may also contribute to the small size of the LTC insurance market. For instance, insurance loads in this arena appear to be unusually large compared to other insurance markets, although Brown and Finkelstein (2011) show that even these loads are not large enough to explain the small size of the market. Moreover, large loads may be a consequence of the small market, rather than its cause, due to the impossibility of benefiting from economies of scale. Nursing homes may crowd out the provision of care by family members (Pauly, 1990), although this observation does not explain why people without children also fail to purchase long-term insurance. Additional explanations include the possibility of using one's home equity to pay for care (Davidoff, 2010); a decrease in marginal utility following health deterioration (Finkelstein, Luttmer, and Notowidigdo, 2013); and the idea that bequests are luxury goods (Lockwood, 2014).
} 
are more likely to accept investments when returns are aggregated in terms of a portfolio than when they are shown each asset's returns separately (Redelmeier and Tversky, 1992; Langer and Weber, 2001). Likewise, people take less risk when they are shown returns more, versus less, frequently (Gneezy and Potters, 1997). Narrow framing is also an important ingredient of theories seeking to explain risk aversion over small gambles (Rabin and Thaler, 2001; Safra and Segal, 2008). ${ }^{4}$

Narrow framing may be especially problematic when buying insurance. The purpose of insurance is to alleviate the impact of losses, so failure to evaluate the potential benefits of avoiding the losses alongside the costs of insurance can make buying an insurance product seem undesirable. Indeed our theoretical model shows that individuals who are subject to narrow framing will buy less insurance. Consistent with this view, Kunreuther and Pauly (2012: 1) argued that "there is a tendency to view insurance as a bad investment when you have not collected on the premium you paid the insurer. It is difficult to convince people that the best return on an insurance policy is no return at all." Yet there is little empirical evidence regarding the impact of narrow framing in insurance. One exception is Brown et al. (2008) who suggested that many people perceive life annuities as "risky investments." That study found that 72 percent of survey respondents elected an annuity when it was described in terms of consumption flows, but only 21 percent chose it when annuity payments were described in isolation. ${ }^{5}$

To test our theory, we developed and fielded a new module for the Health and Retirement Study (HRS), which allows us to classify people according to how likely they are to narrow frame. We find that, all else equal, individuals who are subject to narrow framing are between 25 and 66 percent less likely to buy long-term care insurance than average. Our estimates are statistically significant and economically large, and they imply that the narrow framing effect is an order of magnitude larger than the effect of adverse selection and risk aversion.

The paper proceeds as follows: Section 2 presents a simple model to motivate our empirical analysis. Section 3 discusses the data, and Section 4 presents our main empirical findings. A final section concludes.

\footnotetext{
${ }^{4}$ Kahneman, Knetsch, and Thaler (1991) argue that narrow framing and loss aversion explain the observed tendency to stick to one's original situation, known as the status quo bias. Benartzi and Thaler (1995) and Barberis and Huang (2008) argue that these can also explain the large difference between returns on stocks and bonds, known as the equity premium puzzle. Behaghel and Blau (2012) argue that narrow framing and loss aversion can account for the spike in social security claims at age 65. Narrow framing is also a key ingredient of the idea of mental accounting, which states that people categorize and evaluate outcomes in separate non-fungible accounts (Thaler 1980; 1999). See Read, Loewenstein, and Rabin (1999) for a survey. Similarly, Choi et al. (2014) find that individuals who violate revealed preference are substantially less wealthy.

${ }^{5}$ Similarly, Beshears et al. (2013) also find that framing affects people's hypothetical annuitization decisions.
} 


\section{Model}

To describe the phenomenon we study, it is helpful to consider a simple model of insurance with narrow framing. We consider individuals with initial wealth $W$ who are subject to a financial loss of $L$ with probability $p$. Insurance policies are available with a proportional loading factor $l \in[0,1-p)$, meaning that each dollar of coverage costs $p+l$. Insurance is actuarially fair if the loading factor is zero. There are two types of individuals: those described by expected utility theory ("broad framers") and those described by prospect theory ("narrow framers").

The preferences of expected utility consumers are described by a (Bernoulli) consumption utility function $U: \mathbb{R}_{++} \rightarrow \mathbb{R}$, which is strictly increasing, strictly concave, and differentiable. Let $I$ denote the the insurance coverage purchased (i.e., the "indemnity"). An expected utility consumer picks coverage $I$ to maximize

$$
p U(W-L+(1-p-l) I)+(1-p) U(W-(p+l) I) .
$$

Evaluating the derivative of this expression at zero coverage $(I=0)$ and at full coverage $(I=L)$, we obtain the following result, originally due to Mossin (1968):

Proposition 1. (Expected Utility) An expected utility consumer buys full coverage if and only if insurance is actuarially fair. Moreover, there exists $\bar{l}>0$ such that an expected utility consumer buys positive coverage if and only if the loading factor is less than $\bar{l}$.

Proof. See Appendix A.

Prospect theory individuals take into account both consumption utility (1) and gain-loss utility. ${ }^{6}$ The gain-loss utility function is

$$
\mathcal{V}(X)=\left\{\begin{array}{c}
v(X) \text { if } X \geq 0 \\
-\lambda v(-X) \text { if } X<0
\end{array},\right.
$$

where $v: \mathbb{R}_{+} \rightarrow \mathbb{R}$ is a weakly concave, differentiable function satisfying $v(0)=0$, and $\lambda>1$ captures the individual's loss aversion. ${ }^{7}$ Formally, because we abstracted from probability

\footnotetext{
${ }^{6}$ This global-plus-local formulation follows, among others, Barberis and Huang (2001), Barberis, Huang, and Santos (2001), Barberis and Xiong (2012), Koszegi and Rabin (2006, 2007), Rabin and Weizsacker (2009), and Heidhues and Koszegi (2008). As is standard in this literature, we abstract from probability weighting for simplicity. As we show in Appendix A, however, our qualitative results do not significantly change if we introduce standard probability weighting functions.

${ }^{7}$ Tversky and Kahneman (1992) suggested a power utility with functional form $v(X)=X^{\alpha}, \alpha \in(0,1]$. The use of the same value function for gains and losses avoids unnecessary notation but is not important for our results.
} 
weighting, a prospect theory individual corresponds to an expected utility individual with Bernoulli utility $u(W+x)+\mathcal{V}(x)$ from payment $x .^{8}$

Buying insurance coverage $I$ corresponds to participating in a lottery that pays $[1-(p+l)] I$ with probability $p$ and $-(p+l) I$ with probability $1-p$. The expected gain-loss utility from insurance is then:

$$
p \mathcal{V}((1-p-l) I)+(1-p) \mathcal{V}(-(p+l) I)=p v((1-p-l) I)-(1-p) \lambda v((p+l) I)
$$

Since the gain-loss utility evaluates insurance in isolation, this individual views insurance as a risky investment profitable if the indemnity received from the insurance company exceeds the premium paid.

Let $\Theta^{E U}$ and $\Theta^{P T}$ denote the levels of wealth, loss amounts, loss probabilities, and loading factors $(W, L, p, l)$ for which zero insurance is optimal. Proposition 2 presents the main testable prediction from our model: controlling for other characteristics, individuals who narrow frame are less likely to buy insurance.

Proposition 2. (Narrow Framing) Let $p \leq \frac{1}{2} . \Theta^{E U} \subset \Theta^{P T}$ and the inclusion is strict.

Proof. See Appendix A.

Proposition 1 holds for any loss aversion coefficient $\lambda>1$ and any concave value function $v$. If one is willing to impose stronger restrictions, the result from Proposition 1 can be substantially strengthened to higher loss probabilities $p$. However, since the important losses covered by most insurance policies happen with probability well below 50 percent, we do not pursue such an approach here, except for the following example: ${ }^{9}$

Example 1. Let $v(x)=x^{\theta}$. The expected gain-loss utility with actuarially fair policies is

$$
p((1-p) I)^{\theta}-(1-p) \lambda(p I)^{\theta}=p(1-p)\left[\frac{1}{(1-p)^{1-\theta}}-\frac{\lambda}{p^{1-\theta}}\right] I^{\theta} .
$$

Thus, zero coverage maximizes gain loss utility if $\lambda>\left(\frac{p}{1-p}\right)^{1-\theta}$ (full coverage maximizes gainloss utility if the inequality is reversed). Tversky and Kahneman (1992) estimated $\theta=0.88$ and $\lambda=2.25$. Under these parameters, the conclusion from Proposition 2 holds for any probability of losses satisfying $p<0.99884$.

\footnotetext{
${ }^{8}$ Notice that, when $v$ is not linear, this function is neither concave nor convex. Therefore, such a consumer is neither risk averse nor risk seeking.

${ }^{9}$ For probability of losses arbitrarily close to 1 , the effect from being risk seeking in the domain of losses dominates and the consumer may prefer to buy as much insurance as possible.
} 
Before we move to empirical evidence on narrow framing in insurance, it is instructive to contrast Propositions 1 and 2. The celebrated theorem of Mossin (1968), described in Proposition 1 , shows that individuals who maximize expected utility will buy full insurance when the (proportional) load $l$ is zero and partial insurance when the load is positive. Typically, non-expected utility theories have indifference curves that are either smooth or have a kink at the point of full insurance. Accordingly, they predict that consumers will demand either just as much or more insurance than does expected utility theory (c.f., Segal and Spivak, 1990). By contrast, when individuals frame their insurance purchases narrowly, they will buy less insurance than with expected utility. Hence, our model departs from Mossin's theorem in the opposite direction, relative to standard first-order risk aversion models. In particular, when $p \leq \frac{1}{2}$, individuals would not buy insurance even when the policies are actuarially fair $(l=0)$ if

$$
(\lambda-1) v^{\prime}(0) \geq U^{\prime}(W-L)-U^{\prime}(W) .
$$

Therefore, they would choose zero coverage if consumption utility is sufficiently concave or they are sufficiently loss averse.

Importantly, individuals in our model view insurance as risky investments, which are profitable if the total amount received from the insurance company exceeds the premium. Hence, the gain-loss utility takes the point of zero insurance (status quo) as the reference point against which outcomes are compared. While this is consistent with the evidence described in the introduction, our results would change under different reference points. For example, individuals who evaluate outcomes relative to full insurance have standard nonexpected utility preferences and, therefore, buy more insurance than under expected utility. We return to the discussion of different reference points in the conclusion.

\section{Data}

To test our hypothesis, we devised and fielded a special module for the 2012 Health and Retirement Study (HRS), a nationally representative and in-depth panel study of around 19,000 age-eligible Americans older than age 50 who are interviewed every other year for life (NIA 2014). At baseline, every respondent is resident in the community; thereafter the HRS continues to follow respondents even if they move into assisted living or some other arrangement. Each wave, the HRS also includes several experimental modules, which are randomly assigned to a subset of respondents. The purpose of these modules is to evaluate new questions and examine alternative ways to get at concepts of interest to researchers. Responses to each module can be linked to respondent variables in the Core survey as well. We designed a short survey (see Appendix B), which was one of 10 experimental modules 
assigned randomly to the HRS sample and given to about 1,900 HRS respondents. Response rates averaged 85 percent for about 1,700 completed surveys per module. While the main body, or the Core, of the survey takes more than an hour to complete, modules are limited to an average length of 2-3 minutes per person. Our module focused on the central question of whether people are sensitive to framing, and if so, how this influences the outcome of most interest here, namely whether they have long-term care insurance. ${ }^{10}$ Following Hendren (2013), we drop respondents living in a nursing home at the time of the survey, as they probably would not qualify for LTC insurance. We obtain essentially the same estimates when we include them.

\section{Narrow Framing of Losses}

To explore whether people narrowly frame losses, our HRS module presented respondents with questions about choices involving risk. Our particular interest focuses on two hypothetical questions exposing respondents to narrow framing and loss aversion in a public policy context, based on work by Tversky and Kahneman (1981).

In the first presentation, the following policy-type risk question was asked: ${ }^{11}$

Imagine that the United States is preparing for the outbreak of an epidemic expected to kill 600 people. Two alternative programs to combat the disease have been proposed. Scientists estimate that the outcome of each program is as follows:

- If Program A is adopted, 300 people will be saved.

- If Program B is adopted, there is a 50-50 chance that either 600 people will be saved or none will be saved.

Which program would you favor: Program A or Program B?

In the second presentation, the following question was posed:

Imagine that the United States is preparing for the outbreak of an epidemic expected to kill 600 people. Two alternative programs to combat the disease have been proposed. Scientists estimate that the outcome of each program is as follows:

\footnotetext{
${ }^{10}$ For variable definitions see Appendix B.

${ }^{11}$ By departing from questions involving money lotteries, these questions permit us to measure loss aversion in individuals who are otherwise averse to gambling for reasons unrelated to risk preferences (e.g., for religious reasons).
} 
- If Program A is adopted, 300 people will die.

- If Program B is adopted, there is a 50-50 chance that either none will die or 600 people will die.

Which program would you favor: Program A or Program B?

We randomly assigned participants in terms of who saw each question first, and all participants responded to both questions. Their answers were uncorrelated with the order in which the questions were asked.

Individuals who do not narrow frame should pick the same program in both questions. As described by Tversky and Kahneman (1981), those who narrow frame and have a gainloss utility function that is concave over gains and convex over losses (as in equation (2)) may choose the safe program when outcomes are described as gains (first question) and the risky program when described as losses (second question). Accordingly, we use the subjects' responses to construct a narrow framing measure, Narrow Framing, which takes a value of 1 if the respondent selected the safe option in the "300 will be saved" condition and the risky option in the "300 will die" condition, and 0 otherwise. ${ }^{12}$ In our analysis sample, 25 percent of respondents chose the safe option in the first question and the risky option in the second one, and they are then categorized as subject to narrow framing.

To verify whether this pattern reflects narrow framing of losses rather than random mistakes, we also checked the other possible violation of transitivity, namely, picking the risky program in the first question and the safe program in the second one. This pattern was chosen by about 5 percent of respondents. Our results are unchanged if we drop them from our sample, if we classify them as narrow framers, or if we include them along with those who do not narrow frame.

\section{Other Controls}

To control for other potential explanations for our results in multivariate models, we also include several additional factors (for details see Appendix Tables A and B). Included in the set are measures of cautiousness, private information, risk aversion over large stakes, and loss aversion (risk aversion over small stakes).

To measure cautiousness, we follow Finkelstein and McGarry (2006) and create a variable from the 2012 HRS Core indicating the percent of sex-appropriate annual medical exams each individual undertook. Thus if the respondent was female, she received a score based on whether she had had a flu shot, a mammogram and pap smear, and a cholesterol test. Men

\footnotetext{
${ }^{12}$ Details on variable coding appear in Appendix C.
} 
received scores based on whether they had had a flu shot, a prostate test, and a cholesterol test.

To account for the possibility that a respondent might have private information regarding his need for long-term care, as well as to account for possible non-insurability, we follow Finkelstein and McGarry (2006) and Hendren (2013) by controlling for respondents' subjective probability of needing LTC. This is measured by their answer to the question: "What is the percent chance (0-100) that you will move to a nursing home in the next five years?"

The risk aversion questions focus on lotteries with large stakes and the measure we derive ranges from 1 to 4 indicating coefficients of relative risk aversion implied by respondents' answers (Barsky et al., 1997). Since the HRS discontinued these questions post-2006, we only have risk aversion measures for the one-third of our respondents who entered the survey prior to that year. ${ }^{13}$ This sample restriction is not endogenous, however, and our results are qualitatively unchanged if we drop the risk aversion question and re-estimate results using the entire sample as we demonstrate below.

Loss aversion (or, more precisely, first-order risk aversion) is captured with several questions about possible small investments and we translate respondents' answers into a loss aversion scale ranging from 1-8, with the higher values indicating ever-higher levels of loss aversion. $^{14}$

Key socio-economic control variables are also included such as the respondent's sex, age, marital status, educational attainment, and race/ethnicity. We also control for several health indicators, including a count of physical functioning limitations, a self-reported health variable, and indicators of whether the respondent smoked, had drinking problems, or a variety of diseases (diabetes, heart/lung problems, high blood pressure, stroke, cancer, or arthritis). Finally, we also include a cognition score, which is a summary measure of work recall and mental status (see Appendix C for details). Interestingly, cognition scores are uncorrelated with narrow framing in our dataset.

\section{Results}

In our full sample $(\mathrm{N}=1,589)$, about one-quarter of respondents are classified as narrow framers, in that they selected the safe option in the "300 will be saved" condition and the risky option in the "300 will die" condition. Interestingly, there are virtually no significant

\footnotetext{
${ }^{13}$ Fortunately, the risk preference measures for those respondents asked the questions in different waves are substantially stable over time (Sahm, 2012).

${ }^{14}$ As Rabin (2000) shows, risk aversion cannot explain risk aversion over lotteries with small stakes. Accordingly, lotteries involving small stakes can be used to measure the loss aversion coefficient $\lambda$ from equation (2). This approach is also used, for example, by Fehr and Goette (2007).
} 
correlations of other control variables and being a narrow framer: the only significant results at conventional levels are for the Male and Cautiousness variables. Men are 8 percent less likely to be narrow framers, whereas individuals classified a s c autious a re 5 p ercent more likely to be narrow framers. In particular, education, cognition, risk aversion, and the health variables are not significantly associated with being a narrow framer. However, consistent with the findings from Benjamin, et al. (2013), loss aversion is negatively correlated with cognition scores.

The main prediction of the model is that, controlling for other variables, narrow framing reduces the demand for LTC insurance. Table 1 presents descriptive statistics regarding LTC insurance and narrow framing. In the full sample, 11.8 percent of respondents have LTC insurance. Broad framers are 47 percent more likely to have LTC insurance than narrow framers $(12.7$ versus 8.7 percent). As we will see next, this relationship persists even after we control for other variables.

\section{Table 1. Narrow Framing and Long-Term Care Insurance}

\begin{tabular}{|cc|c|}
\hline & Has LTC Ins. & No LTC Ins. \\
\cline { 2 - 3 } Broad Framer & $12.74 \%(157)$ & $87.26 \%(1075)$ \\
Narrow Framer & $8.68 \%(31)$ & $91.31 \%(326)$ \\
\hline
\end{tabular}

The full sample $(\mathrm{N}=1,589)$ consists of respondents to our 2012 HRS module nonresident who are not in a nursing home and who do not violate transitivity in the opposite direction to the theory. Cell counts in parentheses. For more detail, see Appendices A and B.

\section{Multivariate Analysis}

To control for the other variables, we estimate two sets of multivariate models (Probit and Linear Probability) of the probability of having LTC insurance. For clarity, in the text we only discuss the factors most commonly used to explain demand for insurance to date - namely, cautiousness, subjective probability of needing care, and, when applicable, risk aversion - as well as narrow framing. (A complete set of results appears in Appendix C.)

Table 2 presents the regression coefficients for the full samples. Columns 1 and 3 report results for a simple model that includes only narrow framing in each case, while Columns 2 and 4 are our preferred specifications where the other controls are also included. Including the controls is influential, particularly in the Probit case, but in all cases and as predicted by the model, individuals who are more subject to narrow framing are significantly less likely to purchase LTC insurance. The statistically significant coefficients (p-values of 0.029 and 0.020 for the Probit and linear probability models, respectively) imply a large economic effect. Other things equal, being subject to narrow framing reduces the demand for LTC 


\section{Table 2. Multivariate Models of Determinants of Long-Term Care Insurance: Probit and OLS}

Sample: Respondents not living in nursing homes, not violating transitivity.

Dependent Variable: Has LTC Insurance

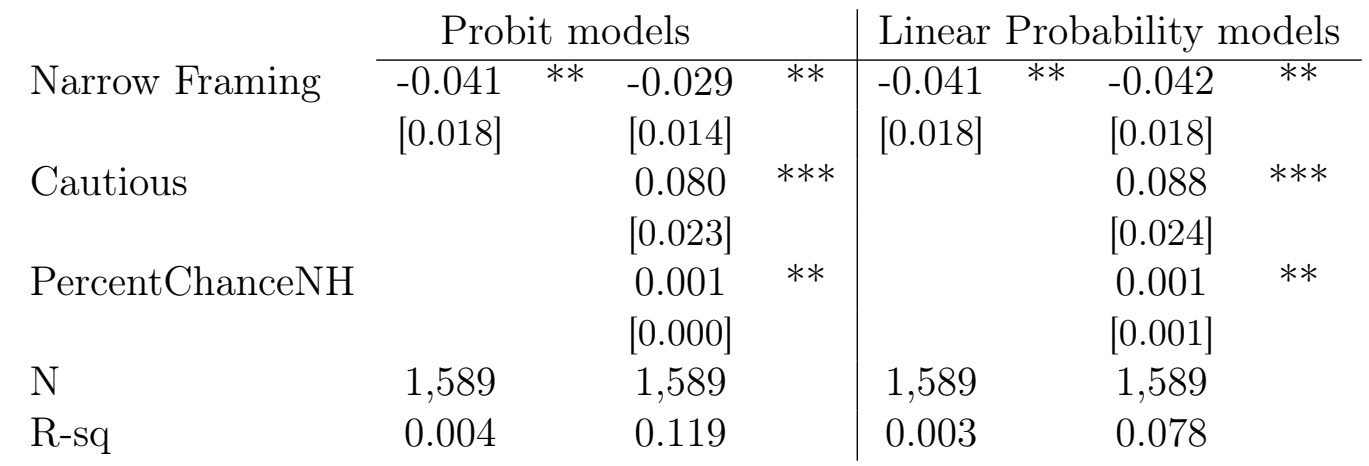

Note: * Significant at 0.10 level, ${ }^{* *}$ Significant at 0.05 level, $* * *$ Significant at 0.01 level. Missing controls included; robust standard errors clustered on households.

Analysis sample consists of the 1,589 respondents to the 2012 HRS module nonresident in a nursing home who do not violate transitivity in the opposite direction of prospect theory. Marginal effects are reported for Probit models. Also included in columns (2) and (4) are controls for age, sex, race/ethnicity, marital status, cognition, health (ADL count, smoking, drinking, depression, diabetes, stroke, heart problems, high blood pressure, lung problems, cancer, arthritis, and loss aversion dummy variables, along with dummies for missing control variables. Robust standard errors are reported, with observations clustered on households. For more detail and results for extended sample, see Appendices A and B.

insurance by 2.9 and 4.2 percentage points according to the Probit and linear probability models. Compared to the base LTC insured rate of 11.8 percent, the estimates imply that narrow framing reduces long-term care insurance demand by between 25 and 35 percent, on average.

Next, we include the risk aversion measure in the regressions; doing so requires us to drop about 1,000 observations. Table 3 presents key results. The estimates of the effect of loss aversion are qualitatively similar, but larger in magnitude compared to the full sample. The coefficients are statistically significant (p-values of 0.004 in both cases) and imply very large effects. All else equal, being classified as a narrow framer reduces the demand for LTC insurance by 5.9 (9.2) percentage points according to the extended Probit (Linear Probability) model. Compared to the base LTC insured rate of 14 percent in this sample, the estimates imply that narrow framing reduces long-term care insurance demand by about 42 (66) percent.

These are very large effects, particularly in comparison with the other key variables. Risk aversion, cautiousness, and the subjective probability of needing care all have the correct sign but are not statistically significant at conventional levels. Moreover, their magnitudes are small in comparison with narrow framing. For example, according to our estimates, a 10 


\section{Table 3. Multivariate Models of Determinants of Long-Term Care Insurance: Probit and OLS}

Sample: Module respondents with risk aversion, not living in nursing homes, not violating transitivity.

Dependent Variable: Has LTC Insurance

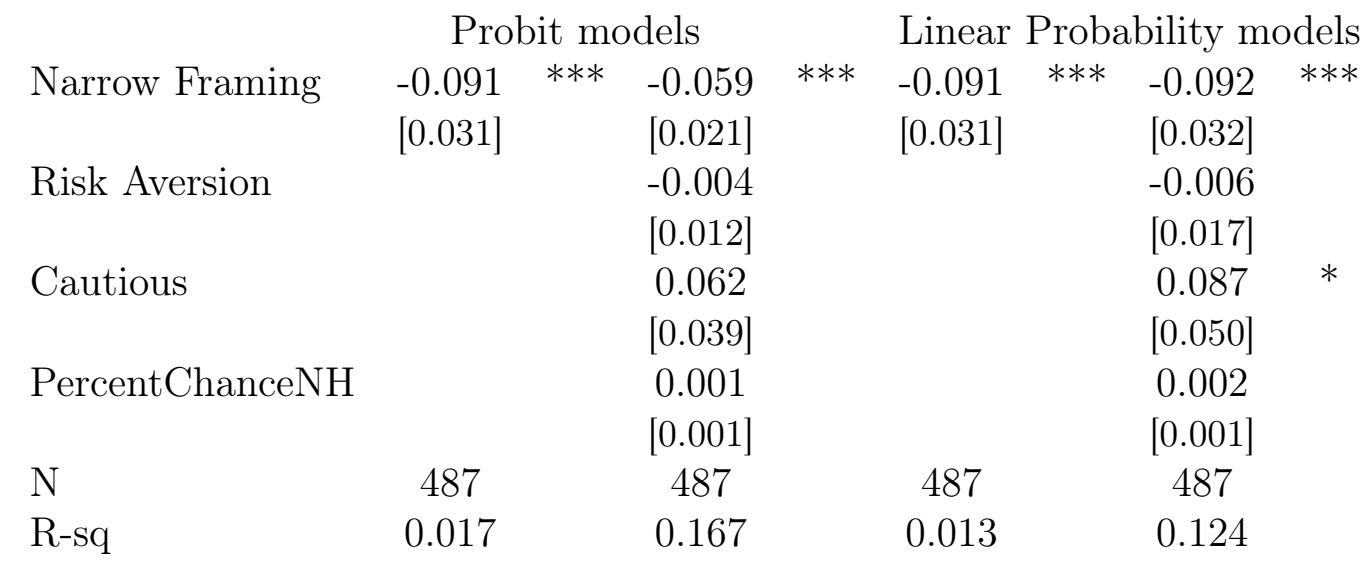

Note: * Significant at 0.10 level, ${ }^{* *}$ Significant at 0.05 level, ${ }^{* * *}$ Significant at 0.01 level. Missing controls included; robust standard errors clustered on households.

Analysis sample consists of the 487 respondents to the 2012 HRS module with answers to the risk aversion question, nonresident in a nursing home, and who do not violate transitivity in the opposite direction of prospect theory. Marginal effects are reported for Probit models. Also included in columns (2) and (4) are controls for age, sex, race/ethnicity, marital status, cognition, health (ADL count, smoking, drinking, depression, diabetes, stroke, heart problems, high blood pressure, lung problems, cancer, arthritis, and loss aversion dummy variables, along with dummies for missing control variables. Robust standard errors are reported, with observations clustered on households. For more detail and results for extended sample, see Appendices A and B.

percentage point increase in the chance of needing care would increase the demand for LTC insurance by a single percentage point. That is, it would take a 59 (93) percentage point increase in the probability of needing-nursing home care for adverse selection, measured by our subjective probability question, to generate the same effect as narrow framing. ${ }^{15}$

Although not statistically significant, risk aversion has the opposite sign as one would expect if consumers were broad framers. More specifically, for individuals who evaluate insurance policies solely in terms of their ability to smooth consumption, insurance purchases should be increasing in risk aversion. By contrast, for consumers whose preferences include both consumption and gain-loss utility, standard measures of risk aversion conflate the con-

\footnotetext{
${ }^{15}$ The difference in estimates with the full sample and with the sample including risk aversion does not appear to be caused by omitted variable bias. When we run the regressions without risk aversion in the sample for which risk aversion measures are available, we obtain the same results as when we include risk aversion. This suggests that HRS respondents not asked the risk aversion questions are less susceptible to narrow framing in the LTC context, perhaps implying some heterogeneity between cohorts not captured by the demographic and other controls.
} 
cavity of their consumption utility with the concavity of their gain-loss utility. As shown in Section 2, each term has an opposite prediction for insurance purchases: concavity of consumption utility induces individuals to buy more insurance, whereas concavity of gainloss utility induces them to buy less insurance. This could explain why the risk aversion coefficient is not only statistically insignificant but also has the "wrong" sign.

As a further robustness check, Table 4 presents coefficient estimates for the same variables as Table 3 when we also include the 27 respondents who violated transitivity in the opposite direction than that predicted by Prospect Theory. These were the respondents who picked the risky program in the "300 will be saved" and the safe program in the "300 will die" question, classifying them as narrow framers as well. Results are nearly identical to those in Table 1: that is, LTC demand is lower by about half for narrow framers, all else equal.

\section{Table 4. Multivariate Models of Determinants of Long-Term Care Insurance: Probit and OLS}

Sample: Module respondents with risk aversion, not living in nursing homes.

Dependent Variable: Has LTC Insurance

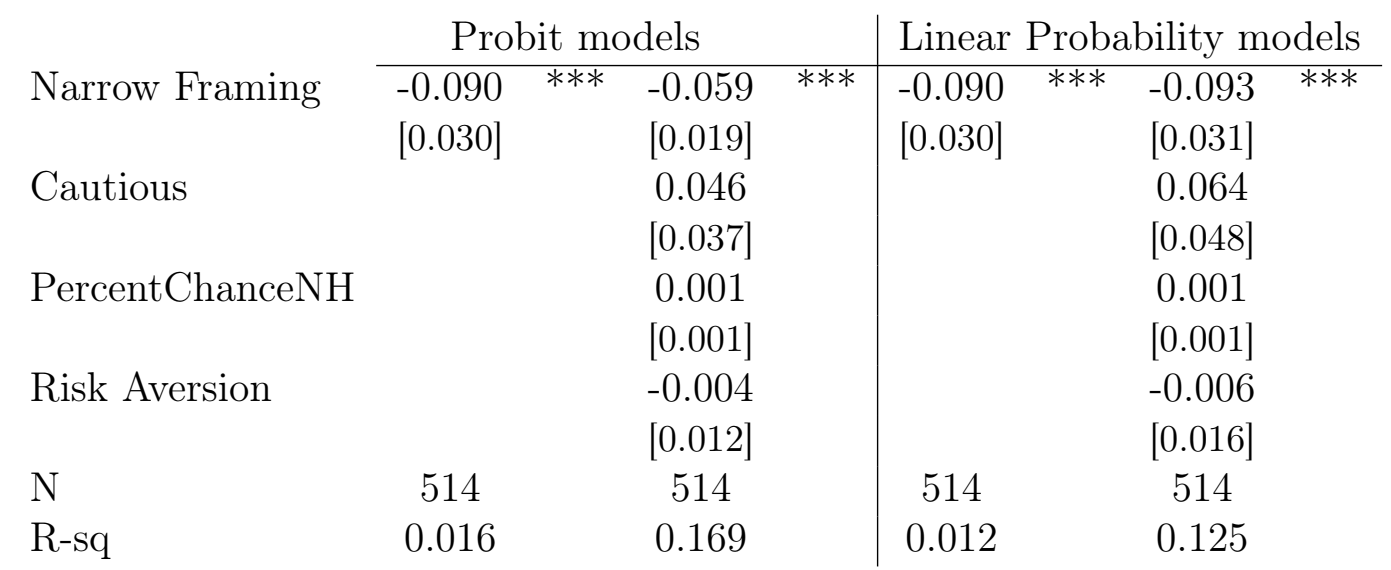

Note: * Significant at 0.10 level, ${ }^{* *}$ Significant at 0.05 level, *** Significant at 0.01 level. Missing controls included; robust standard errors clustered on households.

Analysis sample consists of the 514 respondents to the 2012 HRS module who are nonresident in a nursing home and answers the risk aversion question. Marginal effects are reported for Probit models. Also included in columns (2) and (4) are controls for age, sex, race/ethnicity, marital status, cognition, health (ADL count, smoking, drinking, depression, diabetes, stroke, heart problems, high blood pressure, lung problems, cancer, arthritis, and loss aversion dummy variables, along with dummies for missing control variables. Robust standard errors are reported, with observations clustered on households. For more detail and results for extended sample, see Appendices A and B. 


\section{Conclusion}

We show that narrow framers have a substantially lower demand for long-term care insurance, and the result is robust to controlling on a host of factors including health, cautiousness, risk aversion, probability of needing LTC, and socio-demographics. Moreover narrow framing is a more important deterrent to people's LTC insurance purchases than factors previously suggested, such as risk aversion and private information.

Future work could investigate the importance of narrow framing in other insurance contexts, since economists have been surprised by the low demand for new insurance products that, in theory, should be highly valued. For instance, there has been little demand for home equity insurance protecting homeowners against house price drops, despite the fact that residential equity is the largest and least well-diversified component of most families' wealth in America (Shiller, 2008). Home equity insurance is largely immune from adverse selection and moral hazard concerns because they are mainly indexed policies, so standard insurance theory suggests that people should be willing to pay a considerable amount for them. Narrow framing may explain why consumers have been uninterested in buying these policies.

We should also mention that, while our model predicts that individuals will be reluctant to buy insurance, there are several markets in which consumers seem to be "too eager" to buy insurance. Sydnor (2010), for example, finds that deductible choices in home insurance imply unrealistically large levels of risk aversion. Many consumers also insure small durable goods. ${ }^{16}$ One possible cause for this divergence in preferences may be the effect of framing in different insurance markets, which could shift peoples' reference points. For example, in markets where insurance is relatively uncommon, remaining uninsured may be the natural reference point, whereas in markets where most people have insurance, buying insurance may be the most appropriate reference point. This would be consistent with a model with endogenous reference points as Koszegi and Rabin (2006, 2007). In the present paper, we have also abstracted from probability weighting, which has been shown to be important in some insurance markets. ${ }^{17}$ Understanding which behavioral theories are most relevant to each market is likely a fruitful avenue for future research.

\footnotetext{
${ }^{16}$ See, for example, Cutler and Zeckhauser (2004).

${ }^{17}$ See, for example, Barseghyan et al. (2013) and Abito and Salant (2015).
} 


\section{References}

Abito, J. M. and Y. Salant. 2015. "On the Relevance of Probability Distortions in the Extended Warranties Market.” Working Paper, University of Pennsylvania and Northwestern.

Barberis, N. and M. Huang. 2001. "Mental Accounting, Loss Aversion, and Individual Stock Returns.” Journal of Finance, 56: 1247-1292.

Barberis, N. and M. Huang. 2008. "The Loss Aversion / Narrow Framing Approach to the Equity Premium Puzzle.” Handbook of the Equity Risk Premium, R. Mehra (ed.), North Holland, Amsterdam, 2008.

Barberis, N., M. Huang and T. Santos. 2001. "Prospect Theory and Asset Prices,” Quarterly Journal of Economics 116: 1-53.

Barberis, N. and W. Xiong. 2012. “Realization Utility.” Journal of Financial Economics 104: 251-271.

Barseghyan, L., F. Molinari, T. O’Donoghue, and J. C. Teitelbaum. 2013. “The Nature of Risk Preferences: Evidence from Insurance Choices.” American Economic Review 103(6): 24992529.

Barsky, R., F. T. Juster, M. Kimball, and M. Shapiro. 1997. "Preference Parameters and Behavioral Heterogeneity: An Experimental Approach in the Health and Retirement Study.” Quarterly Journal of Economics 112: 537-579.

Behaghel, L. and D. M. Blau. 2012. "Framing Social Security Reform: Behavioral Responses to Changes in the Full Retirement Age.” American Economic Journal: Economic Policy 4(4): 41-67.

Benartzi, S. and R. Thaler. 1995. “Myopic Loss Aversion and the Equity Premium Puzzle.” Quarterly Journal of Economics 110(1): 73-92.

Benjamin, D. J., S. A. Brown, and J. M. Shapiro. 2013. "Who is 'Behavioral'? Cognitive ability and anomalous preferences.” Journal of the European Economic Association 11(6), 1231-1255.

Beshears, J., J. J. Choi, D. Laibson, B. C. Madrian, and S. P. Zeldes. 2013. "What makes annuitization more appealing?” Journal of Public Economics 116: 2-16. 
Brown, J. and A. Finkelstein. 2008. “The Interaction of Public and Private Insurance: Medicaid and the Long-Term Insurance Market.” American Economic Review 98(3): 10831102.

Brown, J. and A. Finkelstein. 2011. “Insuring Long Term Care in the U.S.” Journal of Economic Perspectives 25 (4): 119-142.

Brown, J. and A. Finkelstein. 2009. “The Private Market for Long-Term Care Insurance in the United States: A Review of the Evidence.” Journal of Risk and Insurance 76: 5-29.

Brown, J., N. Coe, and A. Finkelstein. 2007. “Medicaid Crowd-out of Private Long-term Care Insurance Demand: Evidence from the Health and Retirement Study.” in: Poterba, J.M. Tax Policy and the Economy. Cambridge: MIT Press, Vol. 21: 1-34.

Brown, J., J. Kling, S. Mullainathan, and M. Wrobel. 2008. "Why Don’t People InsureLateLife Consumption? A Framing Explanation of the Under-Annuitization Puzzle.” American Economic Review 98(2): 304-09.

Choi, S., S. Kariv, W. Muller, and D. Silverman. 2014. “Who Is (More) Rational?” American Economic Review 104(6): 1518-1550.

Colombo, F., A. Llena-Nozal, J. Mercier, and F. Tjadens. 2011. “Help Wanted? Providing and Paying for Long-Term Care.” OECD Health Policy Studies. www.oecd.org/els/healthsystems/47836116.pdf

Cutler, D. M, and R. Zeckhauser. 2004. "Extending the Theory to Meet the Practice of Insurance.” In Brookings-Wharton Papers on Financial Services. Eds. R. Litan and R. Herring. Washington, D.C: Brookings Institution.

Davidoff, T. 2010. “Home Equity Commitment and Long-Term Care Insurance Demand.” Journal of Public Economics 94(1): 44-49.

Eyster, E., and G. Weizsäcker. 2011. “Correlation Neglect in Financial Decision-Making.” Working Paper, LSE and DIW Berlin.

Fang, H. 2014. "Insurance Markets for the Elderly.” In J. Piggott and A. Woodland (eds), Handbook of Economics of Population Ageing. Forthcoming.

Fehr, E., and L. Goette. 2007. "Do Workers Work More if Wages Are High? Evidence from a Randomized Field Experiment.” American Economic Review 97(1): 298-317. 
Finkelstein, A., E. Luttmer, and M. Notowidigdo. 2013. "What Good is Wealth Without Health? The Effect of Health on the Marginal Utility of Consumption.” Journal of the European Economic Association 11: 221-258.

Finkelstein, A., and K. McGarry. 2006. "Multiple Dimensions of Private Information: Evidence From the Long-Term Care Insurance Market.” American Economic Review 96(4): 938-958.

Genworth. 2014. Cost of Care Survey 2014. https://www.genworth.com/dam/Americas/US/PDFs/Consumer/corporate/131168-032514Executive-Summary-nonsecure.pdf.

Gneezy, U., and J. Potters. 1997. “An Experiment on Risk Taking and Evaluation Periods.” Quarterly Journal of Economics 631-645.

Heidhues, P., and B. Koszegi. 2008. "Competition and Price Variation when Consumers are Loss Averse.” American Economic Review 92, 1821-1832.

Hendren, N. 2013. "Private Information and Insurance Rejections." Econometrica 81(5): 1713-1762.

Hurd, M., P-C. Michaud, and S. Rohwedder. 2014. "The Lifetime Risk of Nursing Home Use.” In Discoveries in the Economics of Aging, Ed. D. Wise. Chicago: University of Chicago Press, pp 81-209.

Kahneman, D., and D. Lovallo. 1993. "Timid Choices and Bold Forecasts: A Cognitive Perspective on Risk Taking.” Management Science 39(1), 17-31.

Kahneman, D., J. L. Knetsch, and R. H. Thaler. 1991. "Anomalies: The Endowment Effect, Loss Aversion, and Status Quo Bias.” Journal of Economic Perspectives 5(1), 193-206.

Koszegi, B., and M. Rabin. 2006. “A Model of Reference-Dependent Preferences.” Quarterly Journal of Economics CXXI(4): 1133-1165.

Koszegi, B., and M. Rabin. 2007): "Reference-Dependent Risk Attitudes.” American Economic Review 97(4): 1047- 1073.

Kunreuther, H. and M. Pauly. 2012. "Understanding and Improving Insurance Decisions in the Most Misunderstood Industry.” Wharton School Working Paper. 
Langer, T., and M.Weber. 2001. "Prospect Theory, Mental Accounting, and Differences in Aggregated and Segregated Evaluation of Lottery Portfolios.” Management Science 47(5), 716-733.

Lockwood, L. 2014. "Incidental Bequests: Bequest Motives and the Choice to Self-Insure Late-Life Risks.” Working Paper, Northwestern University.

Mossin, J. 1968. “Aspects of Rational Insurance Purchasing.” Journal of Political Economy 76(4), 553-568.

National Institute on Aging (NIA). 2014. Growing Older in America: The Health and Retirement Study.” https://www.nia.nih.gov/health/publication/growing-older-americahealth-and-retirement-study/preface.

OECD. 2010. A System of Health Accounts. Paris: OECD Publications Service.

Pauly, M. 1990. "The Rational Nonpurchase of Long-Term-Care Insurance.” Journal of Political Economy 98(1): 153-168.

Rabin, M. 2000. "Risk Aversion and Expected Utility Theory: A Calibration Theorem.” Econometrica 68(5): 1281-1292.

Rabin, M., and R. H. Thaler. 2001. “Anomalies: Risk Aversion” Journal of Economic Perspectives 15(1): 219-232.

Rabin, M., and G. Weizsäcker. 2009. "Narrow Bracketing and Dominated Choices.” American Economic Review 99(4), 1508-1543.

Read, G. Loewenstein, and M. Rabin. 1999. "Choice Bracketing.” Journal of Risk and Uncertainty 19: 171-97.

Redelmeier, D. A., and A. Tversky. 1992: "On the Framing of Multiple Prospects.” Psychological Science 3: 191-193.

Robert Wood Johnson (RWJ) Foundation. 2014. Long-Term Care: What Are the Issues? Health Policy Snapshot Issue Brief. www.rwjf.org/healthpolicy

Rohwedder, S., M. Oshiro, J. Zissimopoulos. 2011. RAND HRS Data Documentation, Version L. $\quad$ https://www.rand.org/content/dam/rand/www/external/labor/ aging/dataprod/randhrsL.pdf viewed 1/7/15 
Safra, Z., and U. Segal. 2008. "Calibration Results for Non-Expected Utility Theories." Econometrica 76(5), 1143-1166.

Sahm, C. R. 2012. "How Much Does Risk Tolerance Change?” Quarterly Journal of Finance. 2(4):

Segal, U. and A. Spivak. 1990. "First Order versus Second Order Risk Aversion.” Journal of Economic Theory 51(1): 111-125.

Shiller, R. J. 2008. “Derivatives Markets for Home Prices.” Discussion Paper Working Paper No. 46, Yale University.

St. Clair, P., D. Bugliari, N. Campbell, S. Chien, O. Hayden, M. Hurd, R. Main, A. Miu, Moldoff, C. Panis, P. Pantoja, A. Rastegar, J. Zissimopouls. 2011. RAND HRS Data Documentation, Version L: Labor \& Population Program, RAND Center for the Study of Aging.

Sydnor, J. 2010. “(Over)insuring Modest Risks.” American Economic Journal: Applied Economics 2(4): 177-99.

Thaler, R. H. 1999. "Mental Accounting Matters.” Journal of Behavioral Decision Making 12(3): 183-206.

Thaler, R. H. 1980. "Toward a Positive Theory of Consumer Choice.” Journal of Economic Behavior \& Organization 1(1): 39-60.

Tversky, A., and C. R. Fox. 1995. “Ambiguity Aversion and Comparative Ignorance.” The Quarterly Journal of Economics. 110 (3): 585-603.

Tversky, A., and D. Kahneman. 1981. "The Framing of Decisions and the Psychology of Choice.” Science 211 (4481): 453-458.

Tversky, A., and D. Kahneman. 1992. "Advances in Prospect Theory: Cumulative Representation of Uncertainty.” Journal of Risk and Uncertainty 5(4): 297-323. 


\section{Appendix A}

\section{Proofs}

Proof of Proposition 1. The derivative of (1) evaluated at $I=L$ is $-l U^{\prime}(W-(p+l) L)$, which is negative whenever $l>0$. Since the expression in (1) is strictly concave, it is optimal to buy full insurance if and only $l=0$.

The derivative of $(1)$ evaluated at $I=0$ is

$$
p(1-p-l) U^{\prime}(W-L)-(1-p)(p+l) U^{\prime}(W),
$$

which is positive if

$$
\frac{p}{p+l} \cdot \frac{1-p-l}{1-p}>\frac{U^{\prime}(W)}{U^{\prime}(W-L)}
$$

The expression on the left is continuous and decreasing in $l \in[0,1-p]$. Since it equals 1 at $l=0,0$ at $l=1-p$, and the expression on the right is between 0 and 1 , there exists a unique threshold $\bar{l}$ for which such inequality holds.

Proof of Proposition 2. We claim that $I=0$ is the unique maximum of the expected gainloss utility from insurance. The derivative of the expected gain-loss utility (3) with respect to $I$ is

$$
\begin{aligned}
p(1-p-l) v^{\prime}((1-p-l) I)-(1-p)(p+l) \lambda v^{\prime}((p+l) I) & \leq p(1-p)\left[v^{\prime}((1-p) I)-\lambda v^{\prime}(p I)\right] \\
& <p(1-p)\left[v^{\prime}((1-p) I)-v^{\prime}(p I)\right] \\
& \leq 0
\end{aligned}
$$

where the first line follows from $l \geq 0$, the second line follows from $\lambda>1$ (loss aversion), and the third line follows from $(1-p) I \geq p I$ (because $p \leq \frac{1}{2}$ ) and the concavity of $v$. Therefore, if zero coverage maximizes expected consumption utility, it must also maximize the sum of consumption and gain-loss utility. Moreover, because positive coverages give a strictly negative gain-loss utility, the inclusion is strict.

\section{Probability Weighting}

The following example introduces probability weighting in the gain-loss utility function.

Example 2. Consider the functional form suggested by Tversky and Kahneman (1992). The value function is $v(x)=x^{\theta}$ and the probability weighting function is

$$
w(p)=\frac{p^{\gamma}}{\left[p^{\gamma}+(1-p)^{\gamma}\right]^{1 / \gamma}} .
$$


As in expected utility, the consumption utility function is still weighted linearly.

The gain-loss utility when policies are actuarially fair is then

$$
\begin{aligned}
w(p)((1-p) I)^{\theta}-w(1-p) \lambda(p I)^{\theta} & =\left[w(p)(1-p)^{\theta}-w(1-p) \lambda(p)^{\theta}\right] I^{\theta} \\
& =\left[p^{\gamma}(1-p)^{\theta}-(1-p)^{\gamma} p^{\theta} \lambda\right] \frac{I^{\theta}}{\left[p^{\gamma}+(1-p)^{\gamma}\right]^{1 / \gamma}}
\end{aligned}
$$

which is maximized at 0 if and only if

$$
\left(\frac{p}{1-p}\right)^{\gamma-\theta}<\lambda
$$

Rearranging this expression, gives

$$
p>\frac{1}{1+\lambda^{\frac{1}{\theta-\gamma}}} .
$$

Tversky and Kahneman (1992) estimate $\theta=.88, \lambda=2.25$, and $\gamma \approx .65 .{ }^{18}$ Substituting in (4), we obtain that the result from Proposition 2 holds as long as $p>.02858$. Similarly, Tversky and Fox (1995) estimate $\theta=.88, \lambda=2.25$, and $\gamma=.69$, which gives the same result as in Proposition 2 whenever $p>.0138$.

\footnotetext{
${ }^{18}$ They estimate a different weighting function for gains and losses, with parameters .61 and .69, respectively.
} 


\section{Appendix B.}

\section{Variable Construction}

The empirical analysis in the main text focuses on our dependent variable of most interest, 'Has LTC insurance.' This variable is derived from responses to the RAND 2012 HRS Core, ${ }^{19}$ where the question for variable r11hiltc was worded as follows:

[Not including government programs, do] you now have any long-term care insurance which specifically covers nursing home care for a year or more, or any part of personal or medical care in your home?

The response is coded as 1 if $\mathrm{r} 11 \mathrm{hiltc}=1$, and 0 otherwise.

We also control on four important factors: Narrow Framing; Risk averse; Cautious; and PercentChanceNH.

As we described in the text, we create our measure of narrow framing using the answers to two of our module questions. These hypothetical questions, which are based on Tversky and Kahneman (1981), measure whether respondents have different preferences depending on whether outcomes are described in terms of gains or losses. By departing from the investment context, these questions permit us to measure loss aversion in individuals who are otherwise averse to investments for reasons unrelated to risk preferences (e.g., for religious reasons). The order of the questions shown was random. Then the Narrow Framing variable takes a value of 1 if the respondent selected the safe option in the "300 will be saved" condition and the risky option in the "300 will die" condition, and 0 otherwise.

Risk averse: Early waves of the HRS included hypothetical gamble questions widely used in empirical research on risk aversion (Barsky et al., 1997). These questions were, however, discontinued after 2006, so we only have risk aversion measures available for the one-third of our respondents who entered the survey prior to that year. These risk preference measures prove to be substantially stable over time for those respondents asked the questions in several different waves (Sahm, 2012).

Cautious: Following Finkelstein and McGarry (2006), we create a variable from the 2012 HRS Core indicating the percent of sex-appropriate annual medical exams each individual undertook. Thus if the respondent was female, she received a score out of four based on whether she had had a flu shot, a mammogram and papsmear, and a cholesterol test. Men received scores out of three based on whether they had had a flu shot, a prostate test, and a cholesterol test.

\footnotetext{
${ }^{19}$ Data documentation is available at Rohwedder et al. (2011) and St. Clair et al. (2011).
} 
PercentChanceNH: This variable indicates the respondent's self-reported chance out of 100 of being in a nursing home in the next 5 years ( $\mathrm{r}^{*}$ pnhm5y in the Core HRS). If the variable was missing, we created a missing variable flag and imputed a median among those not missing if age $\geq 65$; else $=0$.

Other Controls

All demographic controls are taken from the respondent's HRS Core interview in the RAND files; missing values were recoded to missing and a dummy added in the list of regressors.

Age $=$ na501-birthyr or na501-nx067_r;

Male $=1$ if gender $=1$; male $=0$ if male $=2$;

White $=1$ if raracem $=1,0$ else;

Hispanic $=$ rahispan;

Married $=1$ if $1<=$ r11mstat $<=3$; 0 if $3<=$ r11mstat $<=8$; and

Education year $=$ schlyrs if schlyrs $<=17$.

We used several controls for respondent health taken from the HRS Core, constructed as follows:

Good health: healthgood $=1$ if $1<=$ r11shlt $<=3 ; 0$ if $4<=$ r11shlt $<=5$

Cognition score: $r \operatorname{cog} t o t=\mathrm{r}^{*} \operatorname{cog} t$ tot

ADL summary: radla $=$ r11adla

Smoking: r10smoken

Depression: depression $=1$ if $\mathrm{r} 10$ cesd $>=3,0$ else

Drinking problem: drink $=1$ if $\mathrm{r} 10 \mathrm{drinkn}>=3 ; 0$ else

Diabetes: diabetes $=1$ if $r 10$ diab $=1$ or 3 ; diabetes $=0$ if $r 10$ diab $=0$ or 4

Stroke: stroke $=1$ if $\mathrm{r} 10 \mathrm{strok}=1,2$ or 3 ; stroke $=0$ if $\mathrm{r} 10 \mathrm{strok}=0$ or 4

Heart condition: heart $=1$ if $r 10$ heart $=1$ or 3 ; heart $=0$ if $r 10$ heart $=0$ or 4

High blood pressure: highbp $=1$ if $\mathrm{r} 10 \mathrm{hibp}=1$ or 3 ; highbp $=0$ if $\mathrm{r} 10 \mathrm{hibp}=0$ or 4

Lung disease: lung $=1$ if r10lung $=1$ or 3 ; lung $=0$ if $r 10$ lung $=0$ or 4

Cancer: cancer $=1$ if $r 10$ cancr $=1$ or 3 ; cancer $=0$ if $r 10$ cancr $=0$ or 4

Arthritis: arthritis $=1$ if $r 10 a r t h r=1$ or 3 ; arthritis $=0$ if $r 10 a r t h r=0$ or 4

\section{Loss Aversion}

Two presentations (A and $\mathrm{B}$ ) in the module get at loss aversion; which one a respondent was asked first depended on random assignment, and everyone saw both versions by the end of the module. Presentation A posed the risky choice as having to pay $\$ 100$ to undertake a risky investment, while Presentation B offered the risky investment as a chance of winning money or having to pay. 
When a respondent was randomized to Presentation A of the module, we noted this fact (in a randomization question order variable) and then asked him the following: ${ }^{20}$

- Suppose that a relative offers you an investment that costs you $\$ 100$. If you agree to this investment, there is a 50-50 chance that you would receive either $\$ 215$ or nothing. Would you agree to this investment?

If the answer was affirmative, the person received a less-good offer:

- Now instead, suppose that a relative offers you an investment that costs you $\$ 100$. If you agree to this investment, there is a 50-50 chance that you would receive either $\$ 207$ or nothing. Would you agree to this investment?

If still affirmative, an even less-good offer was as follows:

- Now, suppose that a relative offers you an investment that costs you $\$ 100$. If you agree to this investment, there is a 50-50 chance that you would receive either $\$ 203$ or nothing. Would you agree to this investment?

If the answer to the first question was negative, the branching led to a more attractive offer:

- Now instead, suppose that a relative offers you an investment that costs you $\$ 100$. If you agree to this investment, there is a 50-50 chance that you would receive either $\$ 230$ or nothing. Would you agree to this investment?

If the respondent still said no, he or she would see a yet more attractive offer:

- Now suppose that a relative offers you an investment that costs you $\$ 100$. If you agree to this investment, there is a 50-50 chance that you would receive either $\$ 400$ or nothing. Would you agree to this investment?

Thereafter (or first, if the respondent had been randomized to Presentation B first), the following question was posed:

- Suppose that a relative offers you an investment opportunity for which there is a 50-50 chance you would receive $\$ 115$ or have to pay $\$ 100$. Would you agree to this investment?

An affirmative answer led to this follow-up:

- Now instead, suppose that the same relative offers you a different investment opportunity for which there is a 50-50 chance you would receive $\$ 107$ or have to pay $\$ 100$. Would you agree to this investment?

\footnotetext{
${ }^{20}$ The entire module with all branches appears at http://hrsonline.isr.umich.edu/modules/meta/2012/core/qnaire/online/HRS2012_
} 
And again an affirmative answer led to this less attractive offer:

- Now suppose that the same relative offers you a different investment opportunity for which there is a $50-50$ chance you would receive $\$ 103$ or have to pay $\$ 100$. Would you agree to this investment?

A refusal to accept the first question led to a more positive offer:

- Now instead, suppose that the same relative offers you a different investment opportunity for which there is a $50-50$ chance you would receive $\$ 130$ or have to pay $\$ 100$. Would you agree to this investment?

And another refusal led to this:

- Now suppose that the same relative offers you a different investment opportunity for which there is a $50-50$ chance you would receive $\$ 300$ or have to pay $\$ 100$. Would you agree to this investment?

We then translate participants' answers to these module questions into a loss aversion scale, where the reference category refers to the lowest level of loss aversion (LA1). We create seven additional dummy variables (LA2-8) indicating ever-higher levels of loss aversion. 


\section{Descriptive Statistics}

\begin{tabular}{|c|c|c|c|c|}
\hline \multirow[b]{2}{*}{ Variable } & \multicolumn{2}{|c|}{ Full Sample } & \multicolumn{2}{|c|}{ Subsample with Risk Aversion } \\
\hline & Mean & St. Dev. & Mean & St. Dev. \\
\hline Has LTC insurance $(0,1)$ & 0.12 & 0.32 & 0.14 & 0.35 \\
\hline Narrow framing $(0,1)$ & 0.22 & 0.42 & 0.25 & 0.43 \\
\hline Risk averse (1-4) & & & 3.36 & 1.01 \\
\hline Cautious (0-1) & 0.67 & 0.31 & 0.72 & 0.30 \\
\hline PercentChanceNH (0-100) & 8.29 & 18.11 & 5.50 & 14.34 \\
\hline Age (yrs) & 66.23 & 11.19 & 63.29 & 5.17 \\
\hline Male $(0,1)$ & 0.41 & 0.49 & 0.38 & 0.49 \\
\hline White $(0,1)$ & 0.72 & 0.45 & 0.80 & 0.40 \\
\hline Hispanic $(0,1)$ & 0.12 & 0.32 & 0.10 & 0.30 \\
\hline Married $(0,1)$ & 0.65 & 0.48 & 0.74 & 0.44 \\
\hline Education (yrs) & 12.81 & 2.98 & 13.15 & 2.85 \\
\hline Good health $(0,1)$ & 0.73 & 0.45 & 0.74 & 0.44 \\
\hline Cognition score (12-33) & 22.44 & 3.88 & 23.07 & 2.05 \\
\hline ADL summary $(0-5)$ & 0.27 & 0.81 & 0.21 & 0.76 \\
\hline Smoking $(0,1)$ & 0.16 & 0.36 & 0.16 & 0.37 \\
\hline Depression $(0,1)$ & 0.22 & 0.42 & 0.20 & 0.40 \\
\hline Drinking problem $(0,1)$ & 0.10 & 0.30 & 0.13 & 0.33 \\
\hline Diabetes $(0,1)$ & 0.23 & 0.42 & 0.26 & 0.44 \\
\hline Stroke $(0,1)$ & 0.08 & 0.27 & 0.07 & 0.26 \\
\hline Heart condition $(0,1)$ & 0.23 & 0.42 & 0.22 & 0.42 \\
\hline High blood pressure $(0,1)$ & 0.59 & 0.49 & 0.59 & 0.49 \\
\hline Lung disease $(0,1)$ & 0.09 & 0.28 & 0.09 & 0.29 \\
\hline Cancer $(0,1)$ & 0.14 & 0.34 & 0.11 & 0.31 \\
\hline Arthritis $(0,1)$ & 0.56 & 0.50 & 0.60 & 0.49 \\
\hline Loss averse $2(0,1)$ & 0.02 & 0.13 & 0.01 & 0.11 \\
\hline Loss averse $3(0,1)$ & 0.01 & 0.10 & 0.01 & 0.08 \\
\hline Loss averse $4(0,1)$ & 0.04 & 0.21 & 0.06 & 0.24 \\
\hline Loss averse $5(0,1)$ & 0.02 & 0.15 & 0.02 & 0.13 \\
\hline Loss averse $6(0,1)$ & 0.02 & 0.12 & 0.01 & 0.12 \\
\hline Loss averse $7(0,1)$ & 0.11 & 0.31 & 0.11 & 0.31 \\
\hline Loss averse $8(0,1)$ & 0.63 & 0.48 & 0.61 & 0.49 \\
\hline $\mathrm{N}$ & 1,589 & & 487 & \\
\hline
\end{tabular}

Table 1: Sample consists of respondents to the 2012 HRS nonresident in a nursing home, and not violating transitivity. Subsample with risk aversion excludes those who did not answer the risk aversion question (see text). 


\section{Appendix C. Additional Results for Analysis and Full Sample}

\section{Probit}

With Risk Aversion

Narrow framing

$-0.091-* * *-0.059$

[0.031] [0.021]

Risk aversion

Cautious

PercentChanceNH

Age

$\stackrel{\sim}{\circ}$

Male

White

Hispanic

Married

Education (yrs)

Healthgood

(cont.)
$-0.004$

[0.012]

0.062

[0.039]

0.001

[0.001]

0.001

[0.004]

$-0.029$

[0.027]

$-0.003$

[0.033]

0.000

[0.051]

0.005

[0.029]

0.019 ***

[0.005]

$-0.004$

[0.034]
Full sample With Risk Aversion

\section{OLS}

Full sample

$-0.041 \quad * * \quad-0.029 \quad * *$

[0.018]

[0.014] [0.031]

*

$-0.092$

*** $\quad-0.041$

** $\quad-0.042$

[0.032]

[0.018]

[0.018]

$-0.006$

$[0.017]$

$0.080 \quad * * *$

[0.023]

0.087

[0.050]

$0.001 * *$

0.002

$[0.001]$

0.001

$-0.001$

[0.001]

$-0.017$

[0.014]

0.002

[0.016]

$-0.015$

[0.023]

0.036

[0.014]

0.014

[0.003]

0.027

[0.016]
[0.005]

$-0.036$

[0.037]

$-0.011$

[0.039]

0.014

[0.050]

0.009

[0.036]

0.024

[0.006]

0.001

[0.038]

\begin{tabular}{|c|c|}
\hline $\begin{array}{l}0.088 \\
{[0.024]}\end{array}$ & $* *$ \\
\hline 0.001 & $* *$ \\
\hline$[0.001]$ & \\
\hline-0.002 & \\
\hline$[0.001]$ & \\
\hline-0.016 & \\
\hline [0.018] & \\
\hline 0.000 & \\
\hline [0.018] & \\
\hline-0.002 & \\
\hline$[0.023]$ & \\
\hline 0.04 & $* *$ \\
\hline [0.018] & \\
\hline 0.015 & $* *$ \\
\hline [0.003] & \\
\hline 0.03 & \\
\hline [0.019] & \\
\hline
\end{tabular}




\begin{tabular}{|c|c|c|c|c|}
\hline (cont.) & Prob & & OLS & \\
\hline & With Risk Aversion & Full sample & With Risk Aversion & Full sample \\
\hline Cognition & 0.008 & 0.001 & 0.009 & 0.000 \\
\hline & {$[0.006]$} & {$[0.002]$} & {$[0.008]$} & {$[0.002]$} \\
\hline ADL summary & -0.011 & 0.009 & -0.010 & 0.008 \\
\hline & {$[0.025]$} & {$[0.009]$} & {$[0.020]$} & {$[0.011]$} \\
\hline Smoking & 0.006 & -0.003 & 0.019 & -0.001 \\
\hline & {$[0.036]$} & {$[0.020]$} & {$[0.041]$} & {$[0.020]$} \\
\hline Depression & -0.030 & -0.019 & -0.040 & -0.026 \\
\hline & {$[0.032]$} & {$[0.016]$} & {$[0.037]$} & {$[0.018]$} \\
\hline Drink & -0.044 & -0.010 & -0.077 & -0.020 \\
\hline & {$[0.025]$} & {$[0.021]$} & {$[0.044]$} & {$[0.027]$} \\
\hline Diabetes & -0.027 & -0.001 & -0.039 & -0.008 \\
\hline $\mathcal{J}$ & {$[0.026]$} & {$[0.016]$} & {$[0.036]$} & {$[0.020]$} \\
\hline Stroke & -0.071 & -0.026 & $-0.085 *$ & -0.041 \\
\hline & {$[0.028]$} & {$[0.023]$} & {$[0.048]$} & [0.029] \\
\hline Heart & 0.028 & 0.009 & 0.033 & 0.014 \\
\hline & {$[0.035]$} & {$[0.017]$} & {$[0.044]$} & {$[0.022]$} \\
\hline High blood pressure & 0.006 & 0.006 & 0.008 & 0.007 \\
\hline & {$[0.026]$} & {$[0.014]$} & {$[0.037]$} & {$[0.018]$} \\
\hline Lung & 0.049 & 0.002 & 0.049 & -0.003 \\
\hline & {$[0.065]$} & {$[0.025]$} & {$[0.060]$} & {$[0.029]$} \\
\hline Cancer & 0.081 & 0.032 & 0.09 & 0.043 \\
\hline & {$[0.048]$} & {$[0.021]$} & {$[0.061]$} & {$[0.027]$} \\
\hline Arthritis & -0.028 & 0.000 & -0.036 & -0.001 \\
\hline & {$[0.026]$} & {$[0.014]$} & {$[0.037]$} & [0.019] \\
\hline
\end{tabular}




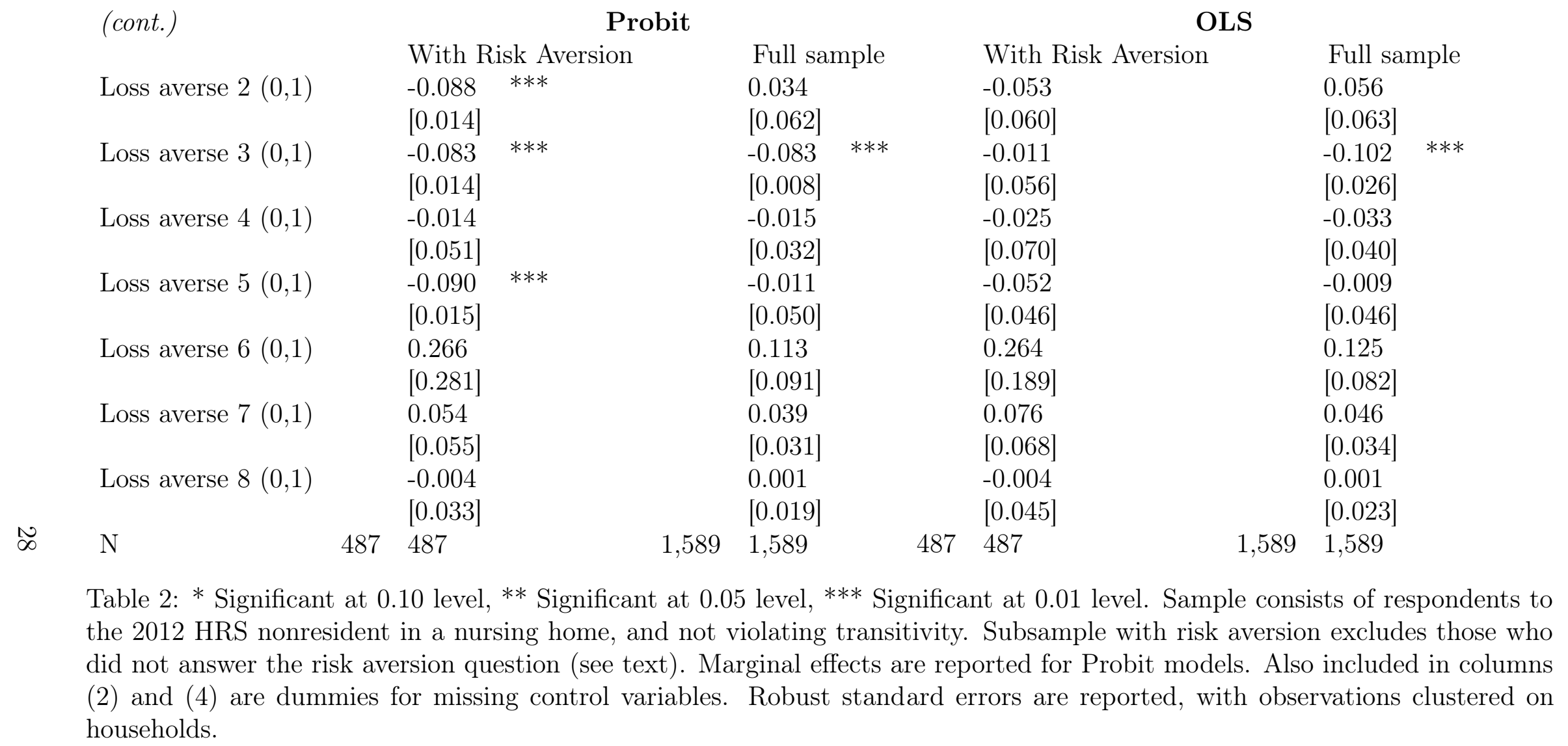

